Roger Williams University

DOCS@RWU

\title{
Latitudinal Differentiation in the Effects of the Toxic Dinoflagellate Alexandrium spp. on the Feeding and Reproduction of Populations of the Copepod Acartia Hudsonica
}

Sean Colin

RogerWilliams University, scolin@rwu.edu

Hans G. Dam

University of Connecticut

Follow this and additional works at: https://docs.rwu.edu/fcas_fp

Part of the Biology Commons

\section{Recommended Citation}

Colin, S. P. and Dam, H. G. 2002. Latitudinal differentiation in the effects of the toxic dinoflagellate Alexandrium spp. on the feeding and reproduction of populations of the copepod Acartia hudsonica. Harmful Algae. 1: 113-125.

This Article is brought to you for free and open access by the Arts and Sciences at DOCS@RWU. It has been accepted for inclusion in Arts \& Sciences Faculty Publications by an authorized administrator of DOCS@RWU. For more information, please contact mwu@rwu.edu. 


\title{
Latitudinal differentiation in the effects of the toxic dinoflagellate Alexandrium spp. on the feeding and reproduction of populations of the copepod Acartia hudsonica
}

\author{
Sean P. Colin*, Hans G. Dam \\ Department of Marine Sciences, University of Connecticut, 1080 Shennecossett Road, Groton, CT 06340, USA
}

Received 1 March 2002; received in revised form 10 March 2002; accepted 20 March 2002

\begin{abstract}
Blooms of the dinoflagellate Alexandrium spp. increase in their frequency, toxicity and historical presence with increasing latitude from New Jersey (USA) to the Gaspé peninsula (Canada). Biogeographic variation in these blooms results in differential exposure of geographically separate copepod populations to toxic Alexandrium. We hypothesize that the ability of copepods to feed and reproduce on toxic Alexandrium should be higher in copepods from regions that are frequently exposed to toxic Alexandrium blooms. We tested this hypothesis with factorial common environment experiments in which female adults of the copepod Acartia hudsonica from five separate populations ranging from New Jersey to New Brunswick were fed toxic and non-toxic strains of Alexandrium, and the non-toxic flagellate Tetraselmis sp. Consistent with the hypothesis, when fed toxic Alexandrium we observed significantly higher ingestion and egg production rates in the copepods historically exposed to toxic Alexandrium blooms relative to copepods from regions in which Alexandrium is rare or absent. Such differences among copepod populations were not observed when copepods were fed non-toxic Alexandrium or Tetraselmis sp. These results were also supported by assays in which copepods from populations both historically exposed and naïve to toxic Alexandrium blooms were fed mixtures of toxic Alexandrium and Tetraselmis sp. Two-week long experiments demonstrated that when copepods from populations naïve to toxic Alexandrium were fed a toxic strain of Alexandrium they failed to acclimate, such that their ingestion rates remained low throughout the entire two-week period. The differences observed among populations suggest that local adaptation of populations of A. hudsonica from Massachusetts (USA) to New Brunswick (Canada) has occurred, such that some populations are resistant to toxic Alexandrium. () 2002 Elsevier Science B.V. All rights reserved.
\end{abstract}

Keywords: Acartia; Adaptation; Alexandrium; Biogeography; Evolution; Feeding deterrence; Red tide algae; Toxin resistance; Zooplankton

\section{Introduction}

It has recently been demonstrated that the ecological relationship between some zooplankton grazers and harmful phytoplankton blooms is closely shaped by their evolutionary history (Hairston et al., 1999;

\footnotetext{
* Corresponding author. Tel.: +1-860-405-9235; fax: +1-860-405-9153.

E-mail address: sean.p.colin@uconn.edu (S.P. Colin).
}

Hairston et al., 2002). Freshwater studies examining the grazer-toxic algae relationship have shown that the populations of Daphnia from lakes where toxic cyanobacteria have bloomed for generations have evolved resistance to the toxic algae (Gilbert, 1990; Hairston et al., 1999; Hairston et al., 2002). The resistance to toxic algae has enabled the zooplankton to feed and grow at higher rates in the presence of the toxic cyanobacteria than Daphnia never exposed to the toxic algae. 
Harmful algal blooms (HABs) in marine environments are increasing worldwide (Hallegraeff, 1993). Since, these blooms only occur in the presence of relaxed grazing pressure, it is important to understand how HAB algae affect zooplankton grazing rates. However, if marine zooplankton populations are able to adapt to the toxic algae, then their relationship to the toxic algae must be examined in the context of the historical exposure of each population to the algae.

The biogeographic characteristics of the toxic dinoflagellate Alexandrium spp. (Balech, 1990) along the northeast coast of North America are ideal to examine whether historical exposure of marine zooplankton affects their ecological relationship with toxic algae. Biogeographic variation in the toxin content and bloom characteristics of the dinoflagellate throughout the Northeast coast of North America has been well documented (Cembella et al., 1988; Anderson et al., 1994; Anderson, 1997). In this region, Alexandrium has two morphospecies that have been linked to the production of paralytic shellfish poisoning (PSP) toxins (A. tamarense and A. fundyense). Blooms of highly-moderately toxic Alexandrium fundyense occur annually along the East Coast of Canada south to Massachusetts Bay. South of Massachusetts Bay there are isolated blooms of A. fundyense and A. tamarense on Cape Cod and the southeast New England coast in enclosed embayments and salt ponds. These southern blooms have lower toxicity and occur less regularly (Maranda et al., 1985; Cembella et al., 1988; Anderson et al., 1994; Anderson, 1997). From detailed surveys of cysts and motile planktonic cells along the New Jersey coast, it is known that A. tamarense occurs in one isolated embayment along the northern New Jersey coast where it has only rarely bloomed, but it is not toxic (Cohn et al., 1988; Mahoney et al., 1995; Anderson, 1997). In addition to higher toxicity levels, Alexandrium blooms in Canada and along the Maine coast have a longer history of occurrence, with the first reported PSP event attributed to Alexandrium sp. in 1889 in eastern Canada (Prakash et al., 1971). The introduction of Alexandrium to more southern waters is believed to have occurred during a large bloom event in 1972 (Anderson et al., 1994). Thus, there appears to be a latitudinal gradient in the historical occurrence, annual frequency and toxicity of Alexandrium blooms from north to south along the east coast of North America.
Biogeographic variation in the blooms results in differential exposure of geographically separate copepod populations to toxic Alexandrium. In this study, we examine the effects of the toxic dinoflagellate, Alexandrium, on copepod grazers from geographically separate populations. We hypothesized that copepod populations from regions which experience frequent and highly toxic blooms of Alexandrium exhibit enhanced fitness parameters when feeding on toxic Alexandrium compared to copepod populations from regions where the blooms rarely occur and are less toxic. We tested this hypothesis with the calanoid copepod, Acartia hudsonica (clausi), which occurs throughout the geographic range of Alexandrium and is the most abundant copepod in coastal waters during toxic blooms in the north (Teegarden et al., 2001).

\section{Materials and methods}

\subsection{Collection and culturing of copepods and algae}

Populations of Acartia hudsonica were collected from Passamaquoddy bay, NB, Canada, Casco bay, ME, Great Pond, MA, Mumford Cove, CT, and Great bay, NJ, using a $200 \mathrm{~mm}$ mesh plankton net. Upon collection, copepods were transported to the laboratory within $24 \mathrm{~h}$. Cohorts of 1000-1500 individuals from each population were separated and cultured under identical conditions following Feinberg and Dam (1998). This method proved to be an efficient and gentle way to maintain separately, for over a year ( $\sim 11$ generations), the different copepod populations with densities of 500-1000 individuals per 201. One concern of maintaining cultures for long periods of time is that their small population sizes may cause genetic drift and decreased genetic variation within the populations. To sustain natural levels of genetic variation, we maintained high copepod densities within the cultures and refreshed the cultures with new individuals from the field each season when $A$. hudsonica was present in the water column.

The copepod cultures were maintained at $12-14{ }^{\circ} \mathrm{C}$ and $12 / 12 \mathrm{~h}$ light/dark (L/D) regime during rearing and experiments. The standard rearing diet consisted of a mixture of Thalassiosira weissflogii, Isochrysis galbana, and Rhodomonas lens, which was kept at a 
concentration of $400-500 \mu \mathrm{gCl}^{-1}$ by replenishment every other day. This concentration is near the saturation level of the functional and numerical response of A. hudsonica. All copepod populations were reared at the same temperature, light and food regimes for several generations to eliminate both maternal effects and environmental variance. This allowed us to attribute the observed differences among populations to genetic variance (Falconer, 1996). Copepods were cultured for 11 generations before the latitudinal experiment, eight generations before the toxicity experiment and five generations before the acclimation experiment.

Three strains of Alexandrium spp., two high-toxin strains and one low-toxin strain, were used for this study (Table 1). The toxic strain of A. tamarense was isolated from Casco bay, ME (CB-307 strain; ME Alexandrium) and a toxic strain of $A$. fundyense from the bay of Fundy, NB, Canada (NB-05 strain; NB Alexandrium). The non-toxic strain of A. tamarense was isolated from Mumford Cove, Connecticut (GTCN-16 strain; CT Alexandrium). The strain from the bay of Fundy was isolated in the laboratory from cysts. All other strains were obtained from various other laboratories. All cultures were grown in F/2 media (Guillard, 1975) at $14^{\circ} \mathrm{C}$ with $12 / 12 \mathrm{~h} \mathrm{~L} / \mathrm{D}$ cycle. The cultures were maintained in exponential growth for use in the experiments by replacing half of the cultured medium with fresh F/2 media each week.

Before each experiment, replicate aliquots of the Alexandrium culture to be used were collected for toxin extraction (Table 1). Toxins were extracted according to Anderson et al. (1994) and analyzed by HPLC using methods of Oshima et al. (1989) in our laboratory (our source for the STX standards was NRC, Halifax, Canada). Of the suite of saxitoxins present in Alexandrium, we quantified the most potent, saxitoxin (STX), neosaxitoxin (NEO), and gonyautoxins I-IV (GTX1-4). Analysis of this suite of toxins was adequate for this study, since toxin analyses were performed only to confirm that the toxic strains were indeed toxic and that the non-toxic strains were non-toxic. Additionally, the toxins that were not analyzed, the B and $\mathrm{C}$ saxitoxins and decarbamoyl saxitoxins, have been found to be the least potent of the toxins (Schatz, 1986; Indrasena and Gill, 1999). More importantly, toxicity levels are not central to this study, since our goal was to examine relative differences among copepods that were fed the same Alexandrium strain.

\subsection{Latitudinal comparison experiments}

Experimental conditions were identical to rearing conditions. A factorial design was used to compare the rate processes of the five A. hudsonica populations given four different diets: three strains of Alexandrium of varying toxicity (Table 1 ; isolated from bay of Fundy, NB; Casco bay, ME; Mumford Cove, CT) and the non-toxic flagellate Tetraselmis sp. Prior to the experiments, none of the copepods had been exposed to toxic Alexandrium. A period of $48 \mathrm{~h}$ before an experiment, 20-25 healthy adult A. hudsonica females

Table 1

Experimental diets. Means of the equivalent spherical diameter (ESD), carbon content and toxicity of each algal strain are shown at the time of the experiments. The Alexandrium strains are identified by the location of collection (CT-Mumford Cove, CT; ME-Casco bay, ME; and NB-bay of Fundy, NB) and the name of the strain

\begin{tabular}{|c|c|c|c|c|}
\hline Experiment and diet & Strain name & $\operatorname{ESD}(\mu \mathrm{m})$ & Carbon $(\mu \mathrm{g} C$ per cell $)$ & $\begin{array}{l}\text { Toxicity (pg STX } \\
\text { equivalent per cell) }\end{array}$ \\
\hline \multicolumn{5}{|l|}{ Latitudinal comparison } \\
\hline CT Alexandrium sp. & GTCN-16 & 26.0 & $2.6 \times 10^{-3}$ & 0.00 \\
\hline ME Alexandrium sp. & CB-307 & 21.5 & $1.5 \times 10^{-3}$ & 5.22 \\
\hline NB Alexandrium sp. & NB-05 & 26.6 & $2.8 \times 10^{-3}$ & 16.12 \\
\hline Tetraselmis sp. & & 8.5 & $5.7 \times 10^{-5}$ & \\
\hline \multicolumn{5}{|l|}{ Mixed diet } \\
\hline ME Alexandrium sp. & CB-307 & 19.6 & $1.1 \times 10^{-3}$ & 4.93 \\
\hline Tetraselmis sp. & & 7.6 & $4.1 \times 10^{-5}$ & \\
\hline \multicolumn{5}{|l|}{ Acclimation } \\
\hline NB Alexandrium sp. & NB-05 & 23.7 & $2.0 \times 10^{-3}$ & 9.25 \\
\hline Tetraselmis sp. & & 7.4 & $3.8 \times 10^{-5}$ & \\
\hline
\end{tabular}


and 10 males were hand picked from the five copepod cultures and placed into separate $1000 \mathrm{ml}$ beakers filled with $0.2 \mu \mathrm{m}$ filtered seawater. The beakers were lightly aerated. After $24 \mathrm{~h}$ the seawater in each of the vessels was replaced. During this $48 \mathrm{~h}$ period, copepods were not fed. This ensured that egg production during the experiments reflected the effects of the experimental diet (Tester and Turner, 1990).

At the end of the starvation period, pairs of females were picked from each population beaker, sized by microscopy, and placed into eight separate $140 \mathrm{ml}$ screw cap bottles containing $70 \mu \mathrm{g} \mathrm{Cl}^{-1}$ of the experimental diet. The choice of food concentration was consistent with concentrations of Alexandrium that the copepods may encounter during natural Alexandrium blooms (Anderson et al., 1983; Watras et al., 1985). Triplicate control bottles contained the diet solution without copepods. The bottles were topped off with the diet solution, sealed to prevent the formation of air bubbles and placed on a plankton wheel, rotating at $1.3 \mathrm{rpm}$ for $24 \mathrm{~h}$. Initial water samples were taken and preserved in a $0.5 \%$ acid lugols solution for later cell counts.

After $24 \mathrm{~h}$, samples were taken and preserved for cell counts. Algal concentrations for Alexandrium were determined from microscopic cell counts using the Utermöhl (1958) technique. Cell counts for Tetraselmis were performed using an Elzone ${ }^{\circledR} 280$ particle counter, where the algal size distribution used to count cells was determined from initial samples and kept constant for final cell counts. Clearance and ingestion rates were calculated using equations from Frost (1972). To determine the carbon content of the diets (Table 1), aliquots from the grazing control bottles were filtered onto combusted $\left(500^{\circ} \mathrm{C}\right.$, $24 \mathrm{~h}$ ) GF/F-filter pads and dried. Carbon content was determined using a Carlo-Erba EA1108 elemental analyzer.

Eggs and copepods were counted and examined for general condition and females were resized. The copepods were then kept for $24 \mathrm{~h}$ in petri dishes containing $0.2 \mu \mathrm{m}$ filtered seawater. After this second incubation, females were checked and the newly laid eggs were counted and added to the egg count from the previous day. This allowed us to calculate gross growth efficiencies (GGE):

GGE $=\frac{\text { carbon growth }}{\text { carbon ingested }}$
The estimate of the GGE assumes that all of the copepod growth was manifested in egg production, which is a reasonable assumption, since there was no significant increase (unpaired $t$-test, $P>0.01$ ) in size of the females before and after the experiment.

From each copepod population, we individually placed four replicates of eight eggs into $250 \mu \mathrm{l}$ wells containing $0.2 \mu \mathrm{m}$ filtered seawater. Hatching rates were determined according to Tang et al. (1998) over 4 days.

The factorial experiments were designed to allow for statistical comparison using a two-way ANOVA (location versus diet) (Sokal and Rohlf, 1981). In this design, we compared the response of the five copepod populations within and among each diet. Post hoc comparisons employed the Tukey-Kramer method.

\subsection{Mixed diet experiment}

To test whether Alexandrium is indeed toxic to A. hudsonica, we carried out experiments with mixed diets. We measured the ingestion and egg production rates of a northern (New Brunswick) and southern (Connecticut) copepod populations given different mixtures of toxic Alexandrium (Maine) and non-toxic Tetraselmis sp. based on the percent of carbon $(100 \%$ Alexandrium $/ 0 \%$ Tetraselmis, 75/25, 50/50, 25/75, $0 / 100$ ). The experimental conditions, starvation and incubation period and methodology were the same as those of the experiment already outlined. The total concentration of each diet was $250 \mu \mathrm{gCl}^{-1}$ which is limiting to the ingestion and growth of A. hudsonica and within the range of Alexandrium blooms. The toxic effects of Alexandrium can be determined by plotting the ingestion and egg production rates versus the percentage of Tetraselmis in the diet (Jónasdóttir et al., 1998; Colin and Dam, 2002). Alexandrium can be considered toxic to grazers if it is present in the mixed diet: (a) reduces the grazers' total ingestion rates; or (b) detracts from the beneficial effects of the control diet by reducing egg production in the food mixtures (Jónasdóttir et al., 1998; Colin and Dam, 2002). This latter point can be examined by drawing a reference line between the egg production at $100 \%$ Alexandrium toxic diet and 100\% Tetraselmis diet. A detrimental effect is suggested when observations of egg production for the food mixtures fall below the reference line. 


\subsection{Acclimation experiment}

Changes in copepod ingestion rates were monitored for 14 days (336h) to determine if the southern $A$. hudsonica population from New Jersey was able to acclimate to the presence of toxic Alexandrium in its diet. Prior to each experiment, adult $A$. hudsonica were maintained in cultures under the standard rearing conditions with the standard diet. Then, 170 female copepods were transferred to a large batch (41) filled with a food solution of 50\% toxic Alexandrium and 50\% Tetraselmis, or a control solution of $100 \%$ Tetraselmis (representing the conditions at $T=0$ ). The total food concentration was maintained at $250 \mu \mathrm{g} \mathrm{Cl}^{-1}$ in the mixture and control diets, a concentration that is typically limiting to the ingestion and growth of $A$. hudsonica. Copepod ingestion rates were determined from $24 \mathrm{~h}$ incubations using $540 \mathrm{ml}$ bottles (three replicates for treatments and two replicates for controls). These were done at different times, $T,(T=24,48,72,120$, 192 , and $336 \mathrm{~h}$ ) with $T$ representing the end of each incubation. Treatment bottles each contained seven females and three males, which had been removed from the large batch container. Environmental conditions were the same as the previously detailed experiments. Control and treatment bottles were kept on a plankton wheel during incubations. At the end of the incubation period, samples were taken for cell counts. Copepods were counted and examined for general condition and returned to the large batch. Cells were counted and ingestion rates measured as described earlier for the latitudinal comparison experiments.

\section{Results}

\subsection{Latitudinal comparison experiment}

To confirm the hypothesis that copepod fitness parameters when feeding on toxic Alexandrium are determined by the historical exposure of copepod populations to the dinoflagellate, two predictions must be met. First, copepod ingestion, egg production, egg hatching or survival rates should be lower in the populations naïve (southern) to toxic Alexandrium than the historically exposed populations (northern). Second, these specific differences between northern and southern copepod populations should not exist in the
Table 2

The ANOVA table of ingestion and egg production rates of the five copepod populations (NJ, CT, MA, ME, NB) feeding on four diets (non-toxic Tetraselmis sp., non-toxic CT Alexandrium, medium-toxin ME Alexandrium, and higher-toxin NB Alexandrium)

\begin{tabular}{lcc}
\hline Source & d.f. & $P$-value \\
\hline Ingestion & & \\
$\quad$ Copepod population & 4 & 0.04 \\
$\quad$ Algal diet & 3 & 0.02 \\
$\quad$ Interaction & 12 & $<0.0001$ \\
Egg production & & \\
$\quad$ Copepod population & 4 & $<0.0001$ \\
$\quad$ Algal diet & 3 & $<0.0001$ \\
Interaction & 12 & $<0.0001$ \\
\hline
\end{tabular}

absence of toxic Alexandrium as a food source. Copepod egg production and ingestion rates when feeding on toxic versus non-toxic diets differed among the copepod populations and diets (Table 2). Post hoc analyses revealed that the relative egg production rates observed among the copepod populations were consistent with both of the above predictions (Fig. 1). When the copepods fed on the toxic Alexandrium strains from New Brunswick (Fig. 1A; NB Alexandrium; Tukey-Kramer, $P<0.05)$ and Maine (Fig. 1B; ME Alexandrium; Tukey-Kramer, $P<$ 0.05; Fig. 1) there was a dramatic decrease, relative to the control diet, in the egg production rates of only the New Jersey and Connecticut copepod populations (Tukey-Kramer, $P<0.05$ ). In contrast, no such decrease was observed with the non-toxic Alexandrium strain from Connecticut (Fig. 1C, CT Alexandrium, ANOVA, d.f. $=4, P=0.1$ ) or non-toxic Tetraselmis sp. (Fig. 1D; Tukey-Kramer, $P>0.05$ ).

The ingestion rates of the copepods from New Jersey relative to the northern copepod populations were also consistent with both of the above predictions. When the copepods fed on the toxic Alexandrium strains from New Brunswick (Fig. 2A; NB Alexandrium; Tukey-Kramer, $P<0.05$ ) and Maine (Fig. 2B; ME Alexandrium; Tukey-Kramer, $P<0.05$; Fig. 1) there was a dramatic decrease in the ingestion rates of only the NJ copepod population (Tukey-Kramer, $P<0.05$ ), while no such decrease was observed for the non-toxic diets (Fig. 2C and D; ANOVA, d.f. $=4$, $P=0.1$ for CT Alexandrium; Tukey-Kramer, $P>$ 0.05 for Tetraselmis sp.). Unlike egg production, the 


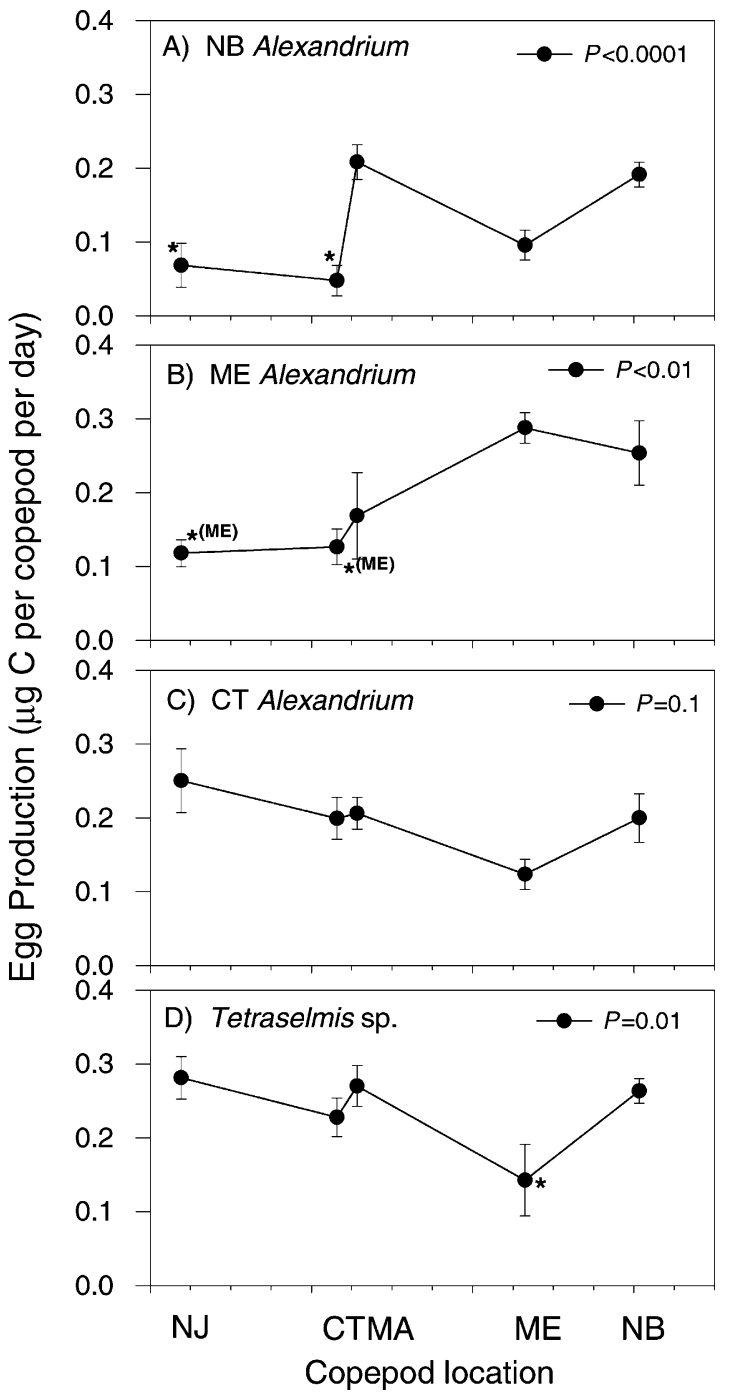

Fig. 1. Mean egg production rates of the five geographically distinct populations of Acartia hudsonica. The origin of each copepod population is identified by location (NB: New Brunswick, ME: Maine, MA: Massachusetts, CT: Connecticut, and NJ: New Jersey) and plotted relative to latitude (NB: $45^{\circ} 04^{\prime}$, ME: $43^{\circ} 39^{\prime}$, MA: $41^{\circ} 34^{\prime}$, CT: $41^{\circ} 19^{\prime}$, CT: $\left.39^{\circ} 23^{\prime}\right)$. Copepods were fed diets containing: (A) high-toxin NB Alexandrium, (B) medium-toxin ME Alexandrium, (C) non-toxic CT Alexandrium, and (D) non-toxic Tetraselmis sp; the mean and S.E. $(n=8)$ are shown; $P$-values for single ANOVA comparing differences among copepod populations are given within figures; asterisks indicate values significantly different from three northern copepod populations (MA, ME, NB) based upon Tukey-Kramer post hoc tests $(P<0.05$, if value is only different from one population which is shown in parentheses); except for $\mathrm{D}$, where asterisks indicate values were significantly different from all other populations.

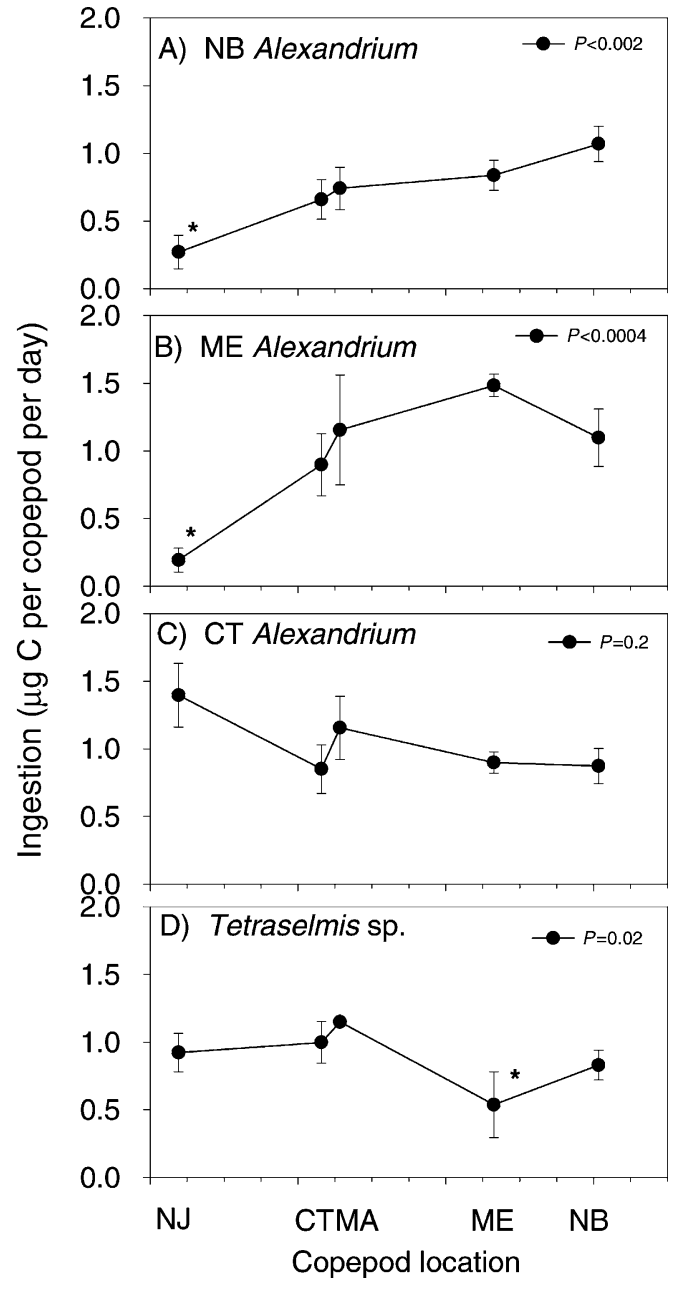

Fig. 2. The mean ingestion rates of the five geographically distinct populations of Acartia hudsonica. The origin of each copepod population is identified by location (NB, ME, MA, CT, and $\mathrm{NJ}$ refer to Fig. 1 for the full form of the abbreviations) and plotted relative to latitude. Copepods were fed diets containing: (A) high-toxin NB Alexandrium, (B) medium-toxin ME Alexandrium, (C) non-toxic CT Alexandrium, and (D) non-toxic Tetraselmis sp; the mean and S.E. $(n=8)$ are shown; $P$-values for single ANOVA comparing differences among copepod populations are given within figures; asterisks indicate values significantly different from all other copepod populations based upon Tukey-Kramer post hoc tests $(P<0.05)$.

ingestion of toxic Alexandrium strains by the CT copepods was not lower than the northern copepod populations (Fig. 2A and B; Tukey-Kramer, $P>0.05$ ).

The toxic strains of Alexandrium did not have lethal effects on any of the individuals from the five copepod 


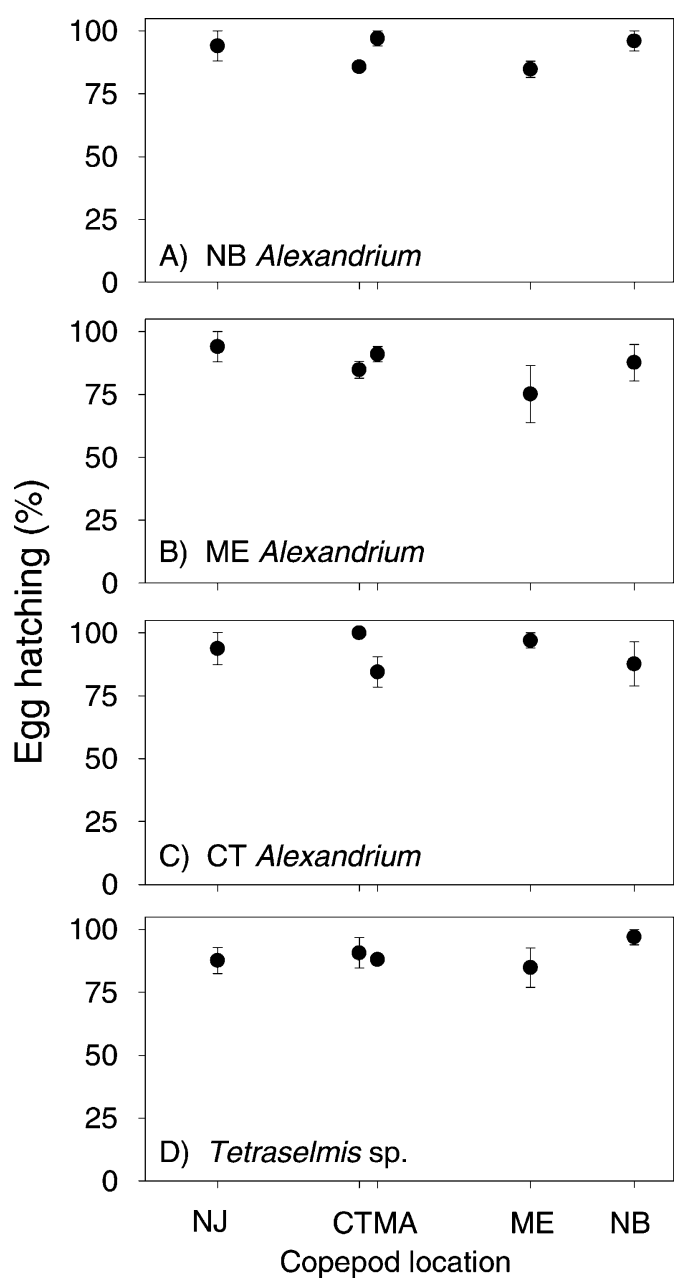

Fig. 3. The mean egg hatching rates of the five geographically distinct populations of Acartia hudsonica. The origin of each copepod population is identified by location (NB, ME, MA, CT, and NJ refer to Fig. 1 for the full form of the abbreviations) and plotted relative to latitude. Copepods were fed diets containing: (A) high-toxin NB Alexandrium, (B) medium-toxin ME Alexandrium, (C) non-toxic CT Alexandrium, and (D) non-toxic Tetraselmis sp; the mean and S.E. $(n=4)$ are shown.

populations. Survival (not shown) was always high, averaging above $90 \%$ regardless of diet.

Egg hatching rates were high and did not significantly differ among diets or within diets among the copepod populations (Fig. 3; ANOVA for arcsine transformed data, $P>0.05$ ).

The GGE ranged from 0.1 to 0.4 and typically varied independent of copepod populations and diets (Fig. 4).

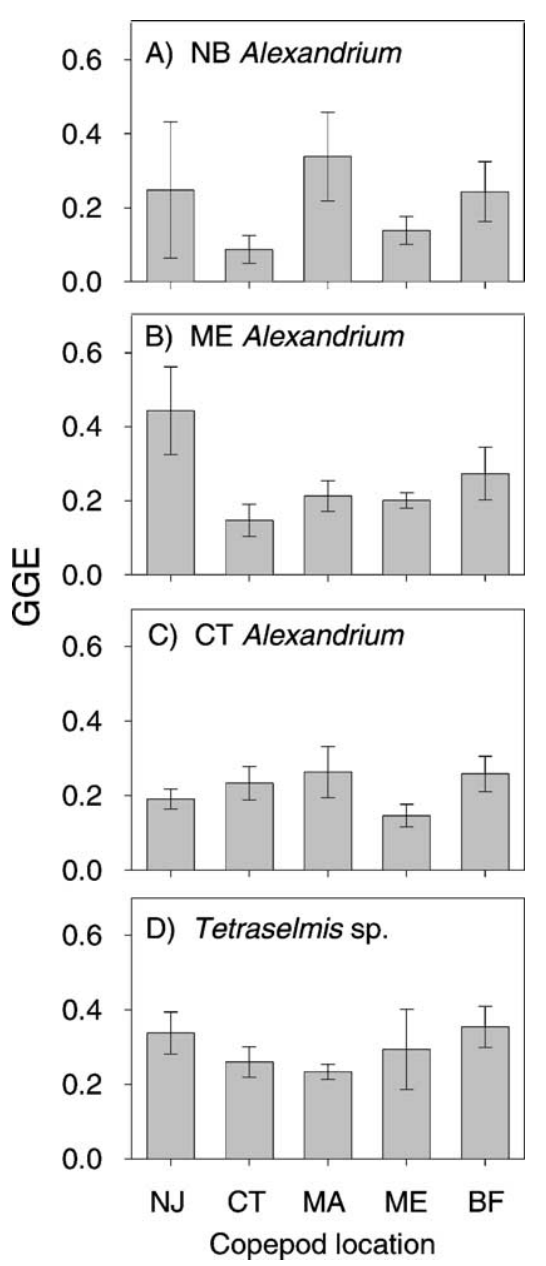

Fig. 4. The GGE of the five Acartia hudsonica populations fed different diets: (A) high-toxin NB Alexandrium, (B) medium-toxin ME Alexandrium, (C) non-toxic CT Alexandrium, and (D) non-toxic Tetraselmis sp.; the mean and S.E. $(n=8)$ are shown.

Only the copepods from Connecticut exhibited significantly lower GGEs when fed the NB Alexandrium strain (arcsine transformed Tukey-Kramer, $P<0.05$ ).

Since, copepod survival, egg hatching or GGE were insensitive to toxic Alexandrium, the latitudinal effects of Alexandrium on copepod fitness are only manifest in their ability to feed and reproduce.

\subsection{Mixed diet experiment}

Since, the comparisons from the factorial experiment utilized sole food diets (i.e. 100\% toxic 


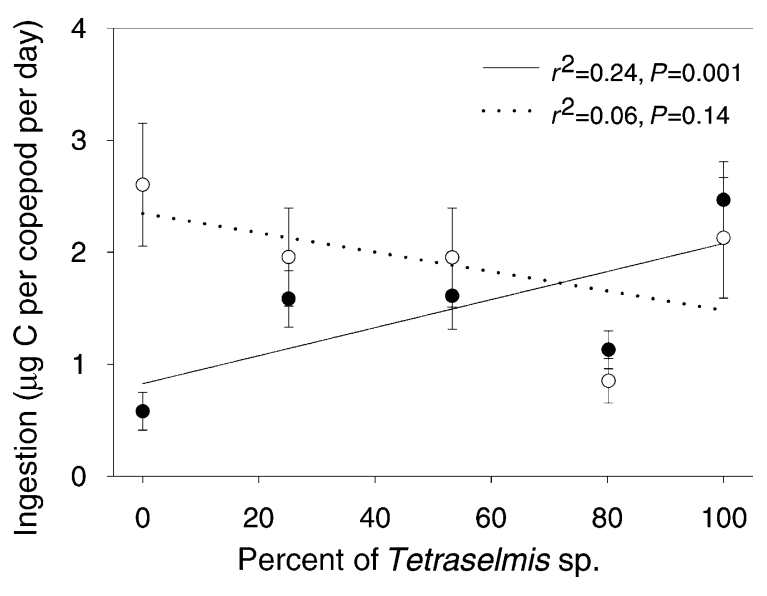

Fig. 5. The mean ingestion rates of NB (circles) and CT (filled circles) copepods vs. the carbon (\%) of Tetraselmis sp. in the diet; mixture diets consist of Tetraselmis and ME Alexandrium (0\% Tetraselmis sp. indicates $100 \%$ Alexandrium); linear regressions for all of the data from each population are shown (NB, dotted; CT, solid); error bars are S.E. $(n=8)$ (refer to Fig. 1 for the full form of the abbreviations).

Alexandrium) we compared the ingestion and egg production rates of a southern (Connecticut) and northern (New Brunswick) copepod population fed different mixtures of toxic Alexandrium and non-toxic Tetraselmis sp. A two-way ANOVA indicated that while the effect was not significant between populations (d.f. $=1, P=0.07$ ) there was a significant interaction (population $\times$ diet, d.f. $=4, P=0.01$ ). Thus, the ingestion rates of populations were affected differently by increased amounts of Alexandrium in the diet. The ingestion rates of copepods from Connecticut decreased as the proportion of toxic Alexandrium in the diet increased (Fig. 5), whereas, the ingestion rates of the copepods from New Brunswick remained unaffected (Fig. 5). Additionally, the CT copepods produced fewer eggs than the NB copepods (two-way ANOVA, d.f. $=1, P=0.04$ ). However, within both the New Brunswick and the Connecticut populations there were no observable differences in egg production rates among diets (Fig. 6).

\subsection{Acclimation experiment}

Since, all of the experiments comparing the copepod populations utilized $24 \mathrm{~h}$ incubation periods, we measured the changes in copepod ingestion in the $\mathrm{NJ}$

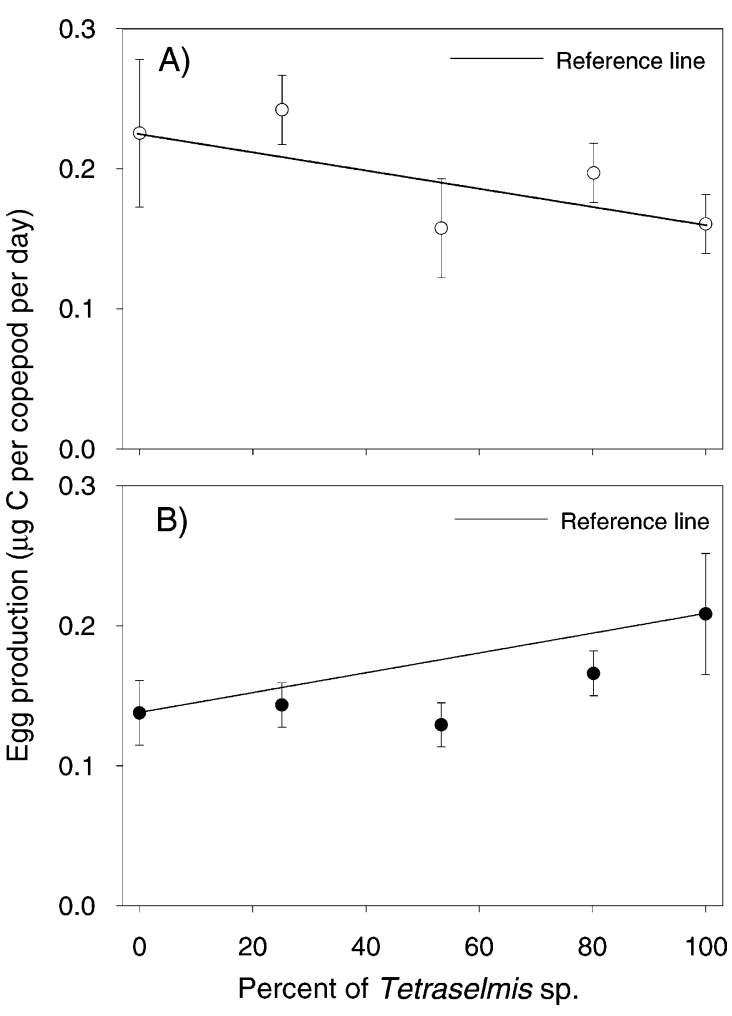

Fig. 6. The mean egg production rates of: (A) NB and (B) CT copepods vs. the carbon (\%) of Tetraselmis sp. in the diet; mixture diets consist of Tetraselmis and ME Alexandrium (0\% Tetraselmis sp. indicates $100 \%$ Alexandrium); the line connecting the mean rates at $100 \%$ Alexandrium and $100 \%$ Tetraselmis sp. is the reference line; error bars are S.E. $(n=8)$.

copepod population over a 14-day period to determine if the copepods were able to physiologically acclimate to toxic Alexandrium. Ingestion rates of the New Jersey Acartia hudsonica fed a 50/50 mix of toxic NB Alexandrium and non-toxic Tetraselmis were significantly lower than their ingestion rates on a control diet of $100 \%$ Tetraselmis (Fig. 7, ANOVA, d.f. $=1$, $P<0.001)$. Ingestion rates on the mixed toxic diet remained consistently low over the 14 days (Fig. 7, linear regression, $P=0.3$ ). Thus, individuals from the New Jersey population were not able to mitigate the negative effects that toxic Alexandrium has on their ingestion rates. There was no significant difference (ANOVA, d.f. $=1, P=0.4$ ) in the ingestion rates of the two components of the mixed diet, Tetraselmis sp. and Alexandrium. 


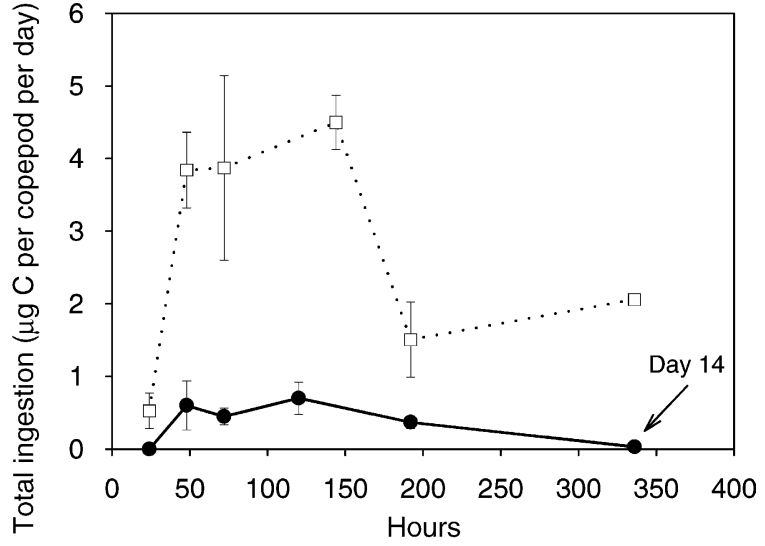

Fig. 7. The NJ copepod population mean ingestion rates on 50/50 mixed diet of toxic NB Alexandrium sp. and Tetraselmis sp. (filled circle) and on a sole diet of non-toxic Tetraselmis sp. (square) measured from $24 \mathrm{~h}$ incubations at different time intervals: times indicate the end times of the incubation periods; error bars are S.E. $(n=3)$ (refer to Fig. 1 for the full form of the abbreviation).

\section{Discussion}

\subsection{Latitudinal differentiation}

Biogeographic differences in populations of conspecifics often arise due to genetic differentiation among the populations. In order for genetic differentiation to occur in the populations with large dispersal capabilities, such as marine copepods, selective pressures must act on the populations (Bucklin and Marcus, 1985; Burton, 1986; Hilbish, 1996). Several studies in marine systems have identified genetically distinct populations of conspecifics, with high dispersal capabilities, which have locally adapted to selective pressures (e.g. copepods, Burton and Feldman, 1981; Burton, 1986; Bradley, 1986; killifish, Powers et al., 1986; softshelled clam, Bricelj et al., 2000, mussel, Koehn et al., 1980; Hilbish and Koehn, 1985, oligochaete, Klerks and Levinton, 1989). Phenotypic variation is due to genetic and environmental variances and their interactions (Falconer, 1996). Hence, genetic differences among populations of conspecifics are often determined by comparing phenotypes of individuals from different populations reared for generations in common environments (Lonsdale and Levinton, 1985; Schultz and Conover, 1997; Boersma et al., 1999). Because our comparisons of ingestion, egg production and hatching rates among geographically separate copepod populations were done after several generations of being reared under common environmental conditions to all populations, we can attribute any of the observed trait differences among the populations to genetic variation (Falconer, 1996; Conover and Schultz, 1995).

The observed differences in the A. hudsonica populations' tolerance to toxic Alexandrium sp. are consistent with local adaptation in some populations to the toxic dinoflagellate. The northern populations (MA, ME, NB), where Alexandrium blooms are most frequent and toxic, exhibited enhanced ingestion and egg production rates when given toxic Alexandrium relative to the two southern populations (Figs. 1A and $\mathrm{B}$ and $2 \mathrm{~A}$ and $\mathrm{B}$ ). These differences are congruous with the environmental "grain" exerted by Alexandrium (as seen in the frequency and toxicity of the blooms) among the geographic locations. However, the rate processes among the copepod populations did not differ when the copepods were fed the non-toxic Alexandrium strain (Figs 1C and D and 2C and D). These results support the idea that the MA, ME and NB copepod populations have evolved toxin resistance to Alexandrium.

While both the southern populations were less tolerant than the three northern populations, we observed tolerance differences between the two southern copepod populations (New Jersey and Connecticut) as well. The copepods from New Jersey could not tolerate either of the higher toxin (NB Alexandrium) or the lower toxin (ME Alexandrium) Alexandrium strains. However, the CT copepods did not exhibit reduced ingestion rates on either of the toxic strains (Fig. 2), although their egg production on the higher toxin strain was reduced (Fig. 1). These results might be related to differences in the presence of toxic Alexandrium in each region. The NJ copepods are from a region where toxic blooms of Alexandrium have not occurred (Cohn et al., 1988; Mahoney et al., 1995); thus, they would not have been exposed to toxic Alexandrium. Without an opportunity to adapt to the toxic dinoflagellate, we would expect the NJ copepods to have the lowest tolerance for Alexandrium. The ingestion rates of the NJ copepods were similar to rates of other Acartia spp. populations fed 
monoalgal diets of toxic Alexandrium (Ives, 1985; Teegarden and Cembella, 1996; Teegarden, 1999). Ives (1985) collected copepods from regions where Alexandrium did not bloom. Teegarden and Cembella (1996) and Teegarden (1999) employed a copepod species, A. tonsa, whose seasonal cycle does not overlap with that of Alexandrium blooms. Hence, in these three studies the copepods were probably naïve to Alexandrium blooms. Likewise, all five copepod populations, in our study, ingested the non-toxic Alexandrium cells at the rates similar to other studies where A. hudsonica (clausi) was fed non-toxic to low-toxic Alexandrium spp. cells (Ives, 1985; Dutz, 1998).

The mixed tolerance that the CT copepods exhibited for toxic Alexandrium could also be related to their exposure history. Toxic Alexandrium has bloomed in the past in the region where the CT copepods were collected; but these blooms were much less frequent and much less toxic than the bloom in the northern regions (Anderson et al., 1994; Anderson, 1997). Additionally, we might expect some genetic exchange between the CT and MA populations due to their proximity. Both of these factors would contribute to the existence of some tolerant individuals in the CT copepod population. Higher genetic variability within the Connecticut population, relative to the New Jersey population, could explain the mixed tolerance we observed in the Connecticut population.

To investigate further the differences in the harmful effects of toxic Alexandrium on the CT copepod population versus a northern (New Brunswick) copepod population, we measured the differences in ingestion and egg production on diets containing different mixtures of ME Alexandrium and Tetraselmis. Despite using a strain with moderate toxin content (about 5 pg STX equivalents per cell, Table 1), we still observed that the northern NB and southern CT copepod populations were affected differently by the presence of toxic Alexandrium in their diet. The CT copepods' ingestion decreased as the amount of toxic Alexandrium increased in the mixed diets, whereas, the NB copepods' ingestion remained unchanged (Fig. 5). Likewise, these differences in ingestion translated into differences in egg production (Fig. 6). However, while it appears the CT copepod's egg production rates fell just below the reference line, the differences among diet mixtures were not significant.
Thus, according to Jónasdóttir et al. (1998), the framework to the test for toxicity, these results show that at this low toxin content, Alexandrium did not have toxic effects on the CT copepods.

The three northern populations (MA, ME, NB) displayed similar ingestion and egg production rates when fed toxic Alexandrium diets (Figs. 1A and B and $2 \mathrm{~A}$ and $\mathrm{B}$ ). The MA copepods were collected from a region where Alexandrium has only bloomed occasionally and has modest toxin content. The ME and NB copepods were collected from regions where Alexandrium blooms are much more frequent, about once per year, and of high-moderate toxin content (Anderson et al., 1994; Anderson, 1997). This inconsistency between the exposure and resistance the three copepod populations to Alexandrium deserves further consideration. The existence of adapted individuals in a population must result by local selection or the immigration of individuals from already adapted populations. In the present case, this would be from the north (Crisp, 1978; Burton, 1986). If adaptation took place in each region, we might expect individuals to be adapted to the particular Alexandrium strain or level of toxicity common to that region. Thus, the copepods from MA would be less resistant to the higher toxin Alexandrium strains, since the blooms in MA are less toxic (Anderson et al., 1994). However, if there were high gene flow among the three copepod populations, then the populations would become less genetically distinct and the geographic range of the resistance to toxic Alexandrium could increase. Since, the resistance of the MA copepods to toxic Alexandrium was similar to the $\mathrm{ME}$ and $\mathrm{NB}$ copepod's tolerance, we could speculate that there is genetic exchange between the MA and northern populations. It is highly reasonable to expect individuals from the ME and NB population to mix due to the circulation in the Gulf of ME (Smith and Schwing, 1991; Anderson et al., 1994). However, Cape Cod has generally been found to be a barrier that restricts the gene flow between populations to its north and south (Schopf, 1979; Buss and Yund, 1989). Nevertheless, the MA population was collected from a site near the Cape Cod Canal, which could readily allow exchange among the populations. Much more work is needed to fully understand the mechanisms involved in making each copepod population resistant to toxic Alexandrium. 


\subsection{Toxic versus feeding deterrent effects}

Both feeding deterrent and incapacitating effects of Alexandrium sp. have been hypothesized to reduce copepod feeding rates on Alexandrium (Huntley et al., 1986; Ives, 1987; Uye and Takamatsu, 1990; Turner et al., 1998). Several studies have found that copepods that ingested toxic Alexandrium often showed erratic behavior and reduced ingestion (Huntley et al., 1986; Ives, 1987; Uye and Takamatsu, 1990). Anecdotally, we observed similarly described erratic behavior. Our mixed diet experiments can be used to examine if the reduction in the ingestion rates of the southern populations were caused by physiological incapacitation or feeding deterrence. A feeding deterrence reduces ingestion rates when given as a sole food, but not when given in a mixed diet (Huntley et al., 1986; DeMott and Moxter, 1991; Turriff et al., 1995; Koski et al., 1999; Teegarden, 1999; Engstrom et al., 2000; Colin and Dam, 2002). In both experiments where Alexandrium was mixed with non-toxic Tetraselmis, the ingestion rates on both the toxic and non-toxic components of the diet decreased (Figs. 5 and 7). Furthermore, the copepods did not appear to select against toxic Alexandrium. Hence, the results of the present study we observed are not consistent with the feeding deterrence hypothesis.

\subsection{Toxic Alexandrium as a selective force}

The documented accounts of grazer adaptation to toxic Alexandrium, including this study and a study on adapted populations of softshell clams (Bricelj et al., 2000), suggest that toxic Alexandrium may exert selective pressure on its grazers. Such selection may be manifested by inducing physiological changes that may alter demographics of a population and by increasing grazer mortality (Travis, 1996). The results of the present study provide direct evidence that the presence of toxic Alexandrium has the potential to alter the demographics of a population by severely reducing the egg production of non-resistant individuals within the population. While we did not observe any mortality in copepods feeding on toxic Alexandrium, some toxic effects that are sub-lethal in laboratory settings, such as physiological incapacitation, may have lethal consequences under natural conditions by increased vulnerability to predation (Newman, 1995).

\section{Conclusion}

We have found that geographically separate copepod populations are affected differently by toxic Alexandrium. These differences are consistent with the hypothesis that some copepod populations have adapted to the presence of toxic Alexandrium. The present study may provide insight to help unravel the disparity among studies examining the grazer-toxic algal relationship (Turner et al., 1998). More importantly, this study demonstrates that historical exposure and evolved resistance of zooplankton populations are important determinants of whether some algae are harmful to zooplankton grazers. Hence, grazer adaptation will affect the fate of HABs and the fate of toxins in marine food webs. Understanding the evolution of grazer resistance is critical to understanding and predicting the effects of the spreading of HABs in marine systems.

\section{Acknowledgements}

We wish to thank Senjie Lin, Eric Schultz and Evan Ward and anonymous reviewers for their constructive comments and suggestions, and those who generously supplied us with algal strains: Jennifer Martin, Nicole Poulton (CB-307 strain from D. Anderson laboratory), Greg Teegarden (GTCN-16 strain), and Gary Wikfors (several non-toxic algae). We thank Karen Steidinger for identifying NB-05 strain. We thank Sheean Haley for toxin analyses. This research was supported by the ECOHAB program (Grants NOAA NA160P1458 and EPA R-826219-01-0) and the Connecticut SeaGrant program (Grant NA86RG0043) awarded to H.G.D., and an EPA STAR fellowship (U-91562701-1) awarded to S.P.C.

\section{References}

Anderson, D.M., Chisholm, S.W., Watras, C.J., 1983. Importance of life cycle events in the population dynamics of Gonyaulax tamarensis. Mar. Biol. 76, 179-189.

Anderson, D.M., Kulis, D.M., Doucette, G.J., Gallagher, J.C., Balech, E., 1994. Biogeography of toxic dinoflagellates in the genus Alexandrium from the northeastern United States and Canada. Mar. Biol. 120, 467-478. 
Anderson, D.M., 1997. Bloom dynamics of toxic Alexandrium species in the northeastern US. Limnol. Oceanogr. 42, 10091022.

Balech, E. 1990. A short diagnostic description of Alexandrium. In: Granéli, E., Sundström, B., Edler, L. and Anderson, D.M. (Eds.), Toxic Marine Phytoplankton, Elsevier, New York, p. 77.

Boersma, M., DeMeester, L., Spaak, P., 1999. Environmental stress and local adaptation in Daphnia magna. Limnol. Oceanogr. 44, 393-402.

Bradley, B.P., 1986. Genetic expression of temperature tolerance in the copepod Eurytemora affinis in different salinity and temperature environments. Mar. Biol. 91, 561-565.

Bricelj, V.M., MacQuarrie, S.P., Twarog, B.M., Trainer V.L., 2000. Evidence for adaptation to toxins in populations of the softshell clam, Mya areneria, subjected to recurrent toxic blooms. In: Proceedings of the Symposium on Harmful Algae in the US (Abstract).

Bucklin, A., Marcus, N.H., 1985. Genetic differentation of populations of the planktonic copepod Labidocera aestiva. Mar. Biol. 84, 219-224.

Burton, R.S., Feldman, M.W., 1981. Population genetics of Tigriopus californicus. Part II. Differentation among neighboring populations. Evolution 35, 1192-1205.

Burton, R.S., 1986. Evolutionary consequences of restricted gene flow among natural populations of the copepod, Tigriopus californicus. Bull. Mar. Sci. 39, 526-535.

Buss, L.W., Yund, P.O., 1989. A sibling species group of Hydractinia in the north-eastern United States. J. Mar. biol. Ass. U.K. 69, 857-874.

Cembella, A.D., Therriault, J.C., Bèland, P., 1988. Toxicity of culture isolates and natural populations of Protogonyaulax tamarensis (Labour) Taylor from the St. Lawrence estuary. J. Shellfish Rev. 7, 611-622.

Cohn, M.S., Mahoney, J.B., Feers, E., 1988. Occurrence of the dinoflagellate, Gonyaulax tamarensis, in New Jersey. Bull. New Jersey Acad. Sci. 33, 45-49.

Colin, S.P., Dam, H.G., 2002. Testing for toxic effects of prey on zooplankton using sole versus mixed diets. Limnol. Oceanogr., in press.

Conover, D.O., Schultz, E.T., 1995. Phenotypic similarity and the evolutionary significance of countergradient variation. Trends Ecol. Evol. 10, 248-252.

Crisp, D.J. 1978. Genetic consequences of different reproductive strategies in marine invertebrates. In: Battaglia, B., Beardmore, J.A. (Eds.), Marine Organisms: Genetics, Ecology, and Evolution. Plenum Press, New York.

DeMott, W.R., Moxter, F., 1991. Foraging cyanobacteria by copepods: responses to chemical defense and resource abundance. Ecology 72, 1820-1834.

Dutz, J., 1998. Repression of fecundity in the neritic copepod Acartia clausi exposed to the toxic dinoflagellate Alexandrium lusitanicum: relationship between feeding and egg production. Mar. Ecol. Prog. Ser. 175, 97-107.

Engstrom, J., Koski, M., Viitasalo, M., Reinikainen, M., Repka, S., Sivonen, K., 2000. Feeding interactions of the copepods Eurytemora affinis and Acartia bifilosa with the cyanobacteria Nodularia sp. J. Plankton Res. 22, 1403-1409.
Falconer, D.S., 1996. Introduction to Quantitative Genetics, 4th Edition. Longman, London.

Feinberg, L.R., Dam, H.G., 1998. Effects of diets on dimensions, density and sinking rates of fecal pellets of the copepod Acartia tonsa. Mar. Ecol. Prog. Ser. 175, 87-96.

Frost, B.W., 1972. Effects of size and concentration of food particles on the feeding behavior of the marine planktonic copepod Calanus Pacificus. Limnol. Oceanogr. 17, 805-815.

Gilbert, J.J., 1990. Differential effects of Anabaena affinis on cladocerans and rotifers: mechanisms and implications. Ecology $71,1727-1740$

Guillard, R.R.L., 1975. Culture of phytoplankton for feeding marine invertebrates. In: Smith, W.L., Chanley, M.H. (Eds.), Culture of Marine Animals. Plenum Press, New York, pp. 26-60.

Hairston Jr., N.G., Lampert, W., Caceres, C.E., Holtmeier, C.L., Weider, L.J., Gaedkes, U., Fischer, J.M., Fox, J.A., Post, D.M., 1999. Rapid evolution revealed by dormant eggs. Nature 401, 446.

Hairston, N.G., Holtmeier, C.L., Lampert, W., Weider, L.J., Post, D.M., Fischer, J.M., Caceras, C.E., Fox, J.A., Gaedke, U., 2002. Natural selection for grazer resistance to toxic cyanobacteria: evolution of phenotypic plasticity? Evolution 55, 2203-2214.

Hallegraeff, G.M., 1993. A review of harmful algal blooms and their apparent global increase. Phycologia 32, 79-99.

Hilbish, T.J., Koehn, R.K., 1985. Exclusion of the role of secondary contact in an allele frequency cline in the mussel Mytilus edulis. Evolution 39, 432-443.

Hilbish, T.J., 1996. Population genetics of marine species: the interaction of natural selection and historically differentiated populations. J. Exp. Mar. Biol. Ecol. 200, 67-83.

Huntley, M.E., Sykes, P., Rohan, S., Marin, V., 1986. Chemically-mediated rejection of dinoflagellate prey by the copepods Calanus pacificus and Paracalanus parvus: mechanisms, occurrences, and significance. Mar. Ecol. Prog. Ser. 28, 105-120.

Indrasena, W.M., Gill, T.A., 1999. Thermal degradation of paralytic shellfish poisoning toxins in scallop digestive glands. Food Res. Int. 32, 49-57.

Ives, J.D., 1985. The relationship between Gonyaulax tamarensis cell toxin levels and copepod ingestion rates. In: Anderson, D.M., White, A.W., Baden, D.G. (Eds.), Toxic Dinoflagellates. Elsevier, New York. pp. 413-418.

Ives, J.D., 1987. Possible mechanisms underlying copepod grazing responses to levels of toxicity in red tide dinoflagellates. J. Exp. Mar. Biol. Ecol. 112, 131-145.

Jónasdóttir, S.H., Kiørboe, T., Tang, K.W., St. John, M., Visser, A.W., Saiz, E., Dam, H.G., 1998. The role of diatoms in copepod production: good, harmless or toxic? Mar. Ecol. Prog. Ser. 172, 305-308.

Klerks, P.L., Levinton, J.S., 1989. Rapid evolution of metal resistance in a benthic oligochaete inhabiting a metal-polluted site. Biol. Bull. 176, 135-141.

Koehn, R.K., Bayne, B.L., Moore, M.N., Siebenaller, J.F., 1980. Salinity related physiological and genetic differences between populations of Mytilus edulis. Biol. J. Linn. Soc. 14, 319-334.

Koski, M., Rosenberg, M., Viitasalo, M., Tanskanen, S., Sjölund, U., 1999. Is Prymnesium patelliferum toxic for copepods? 
Grazing, egg production and egestion of the calanoid copepod Eurytemora affinis in mixtures of "good" and "bad" food. ICES J. Mar. Sci. 56, 131-139.

Lonsdale, D.J., Levinton, J.S., 1985. Latitudinal differentation in copepod growth: an adaptation to temperature. Ecology 66, 1397-1407.

Mahoney, J.B., McGhee, J.A., McNulty, J.K., 1995. Comparison of suitability of Great Bay, New Jersey, and Parsonage creek, New York, for Alexandrium tamarense. J. Euk. Microbiol. 42, $715-721$.

Maranda, L., Anderson, D.M., Shimizu, Y., 1985. Comparison of toxicity between populations of Gonyaulax tamarensis of eastern north American waters. Estur. Cstl. Shelf Sci. 21, 401410.

Newman, M.C., 1995. Quantitative Methods in Aquatic Ecotoxicology. Lewis Publishers, Boca Raton, FL, p. 426.

Oshima, Y., Sugino, K., Yasumoto, T., 1989. Latest advances in HPLC analysis of paralytic shellfish toxins. In: Natori, S., et al. (Eds.), Mycotoxins and Phycotoxins. Proc. 7th In. IUPAC Symposium. Elsevier, Amsterdam, pp. 319-326.

Powers, D.A., Ropson, I., Brown, D.C., Van Beneden, R., Cashon, R., Gonzalez-Villasenor, I., DiMichele, L., 1986. Genetic variation in Fundulus heteroclitus: geographic distribution. Am. Zool. 26, 131-144.

Prakash, A., Medcof, J.C., Tenant, A.D., 1971. Paralytic shellfish poisoning in eastern Canada. Bull. Fish. Res. Bd. Can. 177, $1-87$.

Schatz, E.J., 1986. Chemistry and biology of saxitoxin and related toxins. Ann. New York Acad. Sci. 479, 15-23.

Schopf, T.J.M. 1979. The role of biogeographic provinces in regulating marine faunal diversity through geologic time. In: Gray, J., Boucot, A.J. (Eds.), Biogeography, Plate Tectonics, and the Changing Environment. Corvallis Historical, Oregon State University Press, OR, USA.

Schultz, E.T., Conover, D.O., 1997. Latitudinal differences in somatic energy sorage: adaptive responses to seasonality in an estuarine fish (Atherinidae: Menidia menidia). Oecologia 109, $516-529$.

Smith, P.C., Schwing, F.B., 1991. Mean circulation and variability on the eastern Canadian continental shelf. Continental Shelf Res. 11, 977-1012.
Sokal, R.R., Rohlf, F.J., 1981. Biometry, 2nd Edition. Freeman, San Francisco, New York.

Tang, K.W., Dam, H.G., Feinberg, L.R., 1998. The relative importance of egg production rate, hatching success, hatching duration and egg sinking in population recruitment of two species of marine copepods. J. Plankton Res. 20, 1971-1987.

Teegarden, G.J., Cembella, A.D., 1996. Grazing of toxic dinoflagellates, Alexandrium spp., by adult copepods of coastal Maine: implications for the fate of paralytic shellfish toxins in marine food webs. J. Exp. Mar. Biol. Ecol. 196, 145-176.

Teegarden, G.J., Campbell, R.G., Durbin, E.G., 2001. Zooplankton feeding behavior and particle selection in natural plankton assemblages containing toxic Alexandrium sp. Mar. Ecol. Prog. Ser. 218, 213-226.

Teegarden, G.J., 1999. Copepod grazing selection and particle discrimination on the basis of PSP toxin content. Mar. Ecol. Prog. Ser. 181, 163-176.

Tester, P.A., Turner, J.T., 1990. How long does it take copepods to make eggs? J. Exp. Mar. Biol. Ecol. 141, 169-182.

Travis, J., 1996. The significance of geographical variation in species interactions. Am. Nat. 148, S1-S8.

Turner, T.T., Tester, P.A., Hansen, P.J., 1998. Interactions between toxic marine phytoplankton and metazoan and protistan grazers. In: Anderson, D.M., Cembella, A.D., Hallegraeff, G.M. (Eds.), Physiological Ecology of Harmful Algal Blooms, NATO ASI Series, Vol. G 41. Springer-Verlag, Berlin, pp. 453-474.

Turriff, N., Runge, J.A., Cembella, A.D., 1995. Toxin accumulation and feeding behavior of the planktonic copepod Calanus finmarchicus exposed to the red-tide dinoflagellate Alexandrium excavatum. Mar. Biol. 123, 55-64.

Utermöhl, H., 1958. Zur vevollkommnung der qualitativen phytoplankton-methodik. Mitt. Int. Theor. Agnew. Limnol. 9, $1-38$.

Uye, S., Takamatsu, K., 1990. Feeding interactions between planktonic copepods and red tide flagellates from Japanese coastal waters. Mar. Ecol. Prog. Ser. 59, 97-107.

Watras, C.J., Garcon, V.C., Olson, R.J., Chisholm, S.W., Anderson, D.M., 1985. The effect of zooplankton grazing on estuarine blooms of the toxic dinoflagellate Gonyaulax tamarensis. J. Plankton Res. 7, 891-908. 